\title{
Cathelicidins and Innate Defense Against Invasive Bacterial Infection
}

\author{
VICTOR NIZET ${ }^{1}$ and RICHARD L. GALLO ${ }^{2,3}$ \\ From the ${ }^{1}$ Department of Pediatrics, Division of Infectious Diseases, and ${ }^{2}$ Departments of Pediatrics and Medicine, Division of \\ Dermatology, University of California, San Diego, and ${ }^{3}$ VA San Diego Healthcare System, San Diego, California, USA
}

\begin{abstract}
Cathelicidins are small cationic peptides that possess broad-spectrum antimicrobial activity. These gene-encoded 'natural antibiotics' are produced by several mammalian species on epithelial surfaces and within the granules of phagocytic cells. Since their discovery over a decade ago, cathelicidins have been speculated to function within the innate immune system, contributing to a first line of host defense against an array of microorganisms. Consequently, cathelicidins have captured the interest of basic investigators in the diverse fields of cell biology, immunology, protein chemistry and microbiology. A burgeoning body of experimental research now appears to confirm and extend the biological significance of these fascinating molecules. This article reviews the latest advances in the knowledge of cathelicidin antimicrobial peptides, with particular emphasis on their role in defense against invasive bacterial infection and associations with human disease conditions.
\end{abstract}

V. Nizet, MD, Division of Pediatric Infectious Diseases, University of California, San Diego, 9500 Gilman Drive, Mail Code 0687, La Jolla, CA 92093, USA (Tel. +1 858534 7408, fax. +1 858534 5611, e-mail.vnizet@ucsd.edu)

\section{BASIC BIOLOGY OF CATHELICIDINS}

Cathelicidins are small (12-100 amino acids), cationic and amphipathic in nature, features they share with other major classes of mammalian antimicrobial peptides such as the defensins. While humans and mice each possess a single cathelicidin, other species such as cattle and pigs express many different cathelicidins (1). All cathelicidins are produced as a precursor consisting of an $\mathrm{N}$-terminal signal peptide, a highly conserved prosequence and a structurally variable C-terminal mature peptide (2). It is the presence of the evolutionarily conserved prosequence that assigns an antimicrobial to the cathelicidin class (3). The prosequence is termed the 'cathelin' domain for its homology to cathelin, a protein from porcine neutrophils that inhibits the protease cathepsin L (hence cath-e-L-in). In contrast, the mature Cterminal cathelicidin antimicrobial peptides share little sequence homology, but can be divided into 3 general groups: those forming amphipathic $\alpha$-helices (e.g. human LL-37), those with intramolecular disulfide bonds adopting $\beta$-sheet structure (e.g. porcine protegrins), and those heavily enriched in 1 or 2 amino acids such as proline or arginine (e.g. bovine Bac7) (4). Cathelicidin genes consist of 4 exons and 3 introns: the first 3 exons comprise the signal sequence and cathelin prodomain, while the fourth exon encodes the processing site and variable $\mathrm{C}$-terminal antimicrobial peptide (3). Proteolytic cleavage of the inactive precursor molecule to release the mature $\mathrm{C}$-terminal antimicrobial peptide from the cathelin prodomain is accomplished by elastase (5) or proteinase-3 (6) upon degranulation of activated neutrophils; processing of epithelial cell-derived cathelicidin precursors is less understood. These basic features of cathelicidins are illustrated in Fig. 1.

The single human cathelicidin was cloned from human bone marrow cDNA (7). Its mature form is known as LL-37, since it begins with 2 leucines and is 37 residues in length. An alternative designation assigned to this gene product is hCAP18 (8). This terminology was applied after identification of a human cationic antimicrobial peptide found to have a mass of $18 \mathrm{kDa}$ before processing. In mice, the sole cathelicidin peptide is named CRAMP, for Cathelin-Related Antimicrobial Peptide (9). The mature human (LL-37) and murine (CRAMP) peptides are encoded by similar genes, and have similar $\alpha$-helical structures, spectra of antimicrobial activity and tissue distribution (10). Thus, murine CRAMP can serve as a useful model for in vivo analysis of human cathelicidin function. As will be discussed below, studies of CRAMP in the murine model have provided direct evidence of the importance of endogenous cathelicidin production in immune defense.

\section{ANTIMICROBIAL AND IMMUNE FUNCTIONS OF CATHELICIDINS}

Mature cathelicidin peptides generally exhibit broad-spectrum antimicrobial activity against a range of Gram-positive and Gram-negative bacterial species. Certain cathelicidins are effective at killing nosocomial isolates of Staphylococcus aureus, Enterococcus faecalis or Pseudomonas aeruginosa that are resistant to conventional antibiotic therapy (11). Cathelicidins also show inhibitory activity against certain fungi (e.g. Candida albicans), parasites (e.g. Cryptosporidium parvum) or enveloped viruses (e.g. human immunodeficiency virus). Bacterial killing by cathelicidins is rapid. The mechanism of killing in most cases is thought to involve intercolation and assembly of the peptides within the bacterial membrane to disrupt membrane integrity (12, 13), although certain cathelicidins such as porcine PR-39 reach intracellular targets to block bacterial protein synthesis (14).

The function of cathelicidins is not limited to antimicrobial killing, but extends to other aspects of immunity and 


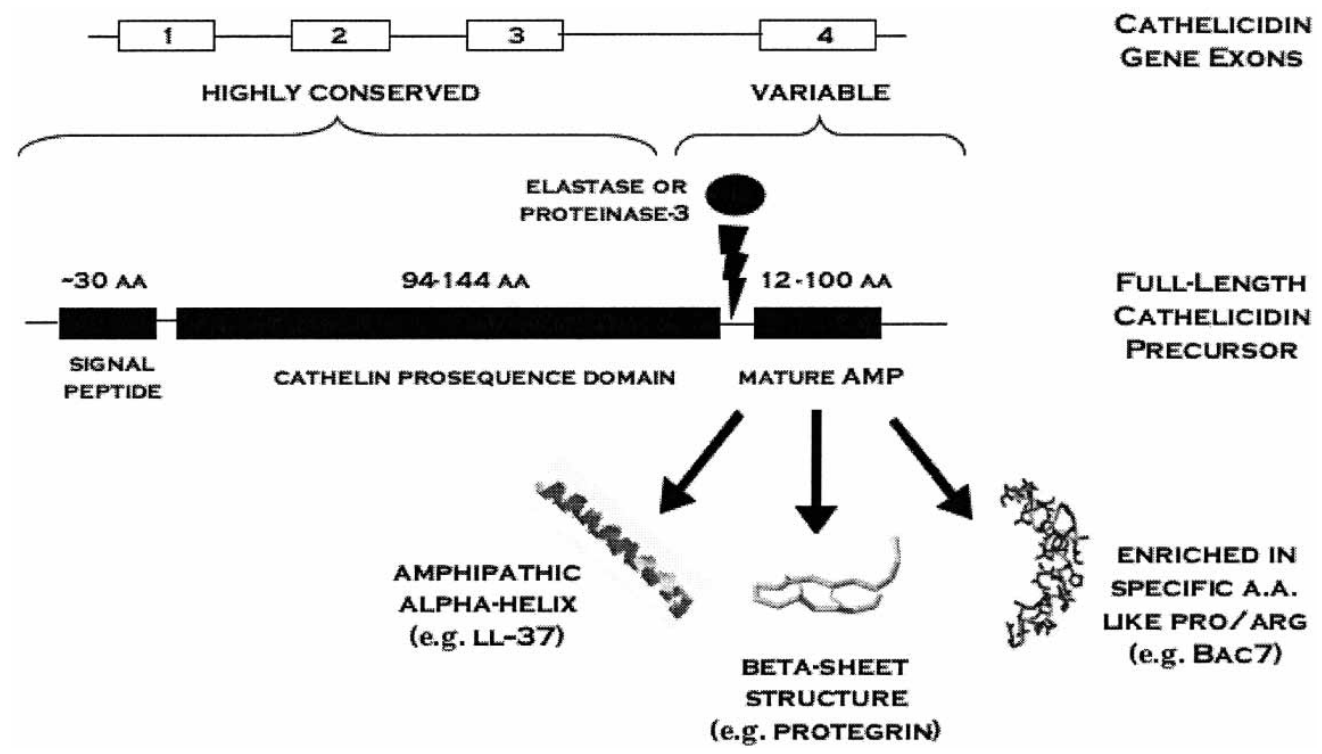

Fig. 1. Gene and protein structures of cathelicidin antimicrobial peptides.

tissue repair. PR-39 from pigs promotes wound healing in skin by stimulating syndecan production and angiogenesis (15). LL-37 binds and neutralizes bacterial lipopolysaccharide (LPS), preventing the induction of inflammatory mediators from monocytes and endothelial cells and inhibiting development of lethal endotoxemia in vivo $(16,17)$. LL-37 can also influence wound repair and has been shown to have additional effects on the host relevant to immune defense. The human cathelicidin up-regulates epithelial expression of chemokine and chemokine receptor genes (18), and itself acts as a chemoattractant for neutrophils, monocytes, Tlymphocytes and mast cells $(19,20)$. In this fashion, LL-37 acts to orient the host immune response by recruitment of leukocytes to the site of infection (18). Microbial killing is effected by phagocytosis and amplified by the robust production of additional cathelicidin by the activated neutrophils (21) and mast cells (22). Because cathelicidins are widely distributed within skin and mucosal epithelial tissues, as well as secretions such as saliva and sweat $(23,24)$, they are ideally situated to serve a sentinel role as multifunctional effectors of innate immunity.

Because cathelicidins possess significant proinflammatory as well as antimicrobial properties, it is important for the host to regulate their production in response to appropriate stimuli. For example, baseline cathelicidin production is very low in normal skin keratinocytes, but is dramatically increased in response to wounding or challenge with the bacterial pathogen Streptococcus pyogenes (25). Cathelicidin production in myeloid cells is similarly induced in response to LPS or bacterial infection $(26,27)$. The production of cathelicidins as an inactive full-length precursor requiring proteolytic activation represents a further level of control. Recently, the function of the highly conserved prodomain was clarified in experiments with recombinant human cathelin. This molecule was shown both to function as a cysteine protease inhibitor and to possess independent antimicrobial activities that were complementary to those of LL-37 (28). The cathelin moiety may simultaneously act to potentiate bacterial killing while limiting tissue injury from microbial and neutrophil-derived proteases. Additional regulation of the inflammatory response may be provided by cytotoxic or proapoptotic effects of cathelicidins on proliferating lymphocytes (29).

\section{EVIDENCE THAT CATHELICIDINS INFLUENCE SUSCEPTIBILITY TO BACTERIAL INFECTION}

An expanding body of experimental research points to an important role for cathelicidins in mammalian defense against bacterial pathogens. Derived from a variety of model systems, these studies can be grouped into 3 complementary avenues of investigation. First, investigations have correlated the in vitro cathelicidin sensitivity or resistance of a particular bacterium with its pathogenic potential. Secondly, evidence exists that blocking cathelicidin production or activation increases immune susceptibility of the host to infectious challenge. Thirdly, therapeutic effects of exogenous cathelicidin administration have been demonstrated against bacterial colonization or disease. Data collected from each of these approaches are summarized in this section.

Certain strains of pathogenic bacteria exhibit intrinsic resistance to cathelicidins and related antimicrobial peptides. Mechanisms underlying this resistance have been characterized in several species, revealing a diverse array of phenotypic strategies to survive cathelicidin killing (Fig. 2). One common pattern of antimicrobial resistance involves bacterial modification of normally anionic constituents of their cell walls with cationic molecules; the net effect of these 


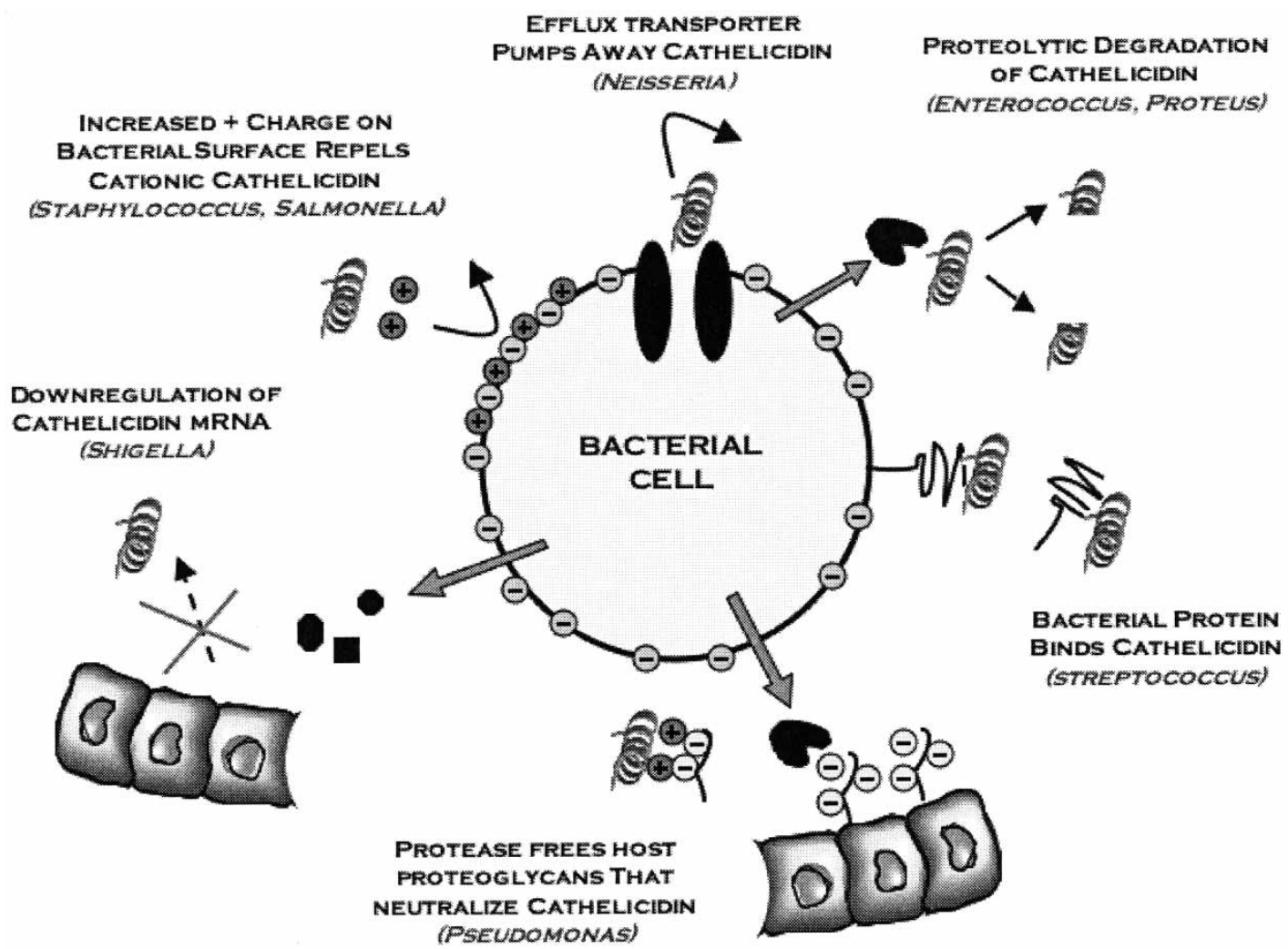

Fig. 2. Potential mechanisms of bacterial resistance to cathelicidin antimicrobial peptides.

substitutions is to decrease the attraction of positively charged cathelicidins to the bacterial cell surface. Cell wall charge alterations associated with cathelicidin resistance in Gram-negative bacteria include covalent modification of the LPS lipid A by acylation or aminoarabinose or the expression of LPS-associated phosphatidylcholine $(30,31)$. Cathelicidin resistance in the Gram-positive pathogen $\mathrm{S}$. aureus is mediated by incorporation of D-alanine within lipotechoic acid or L-lysine within phosphotidylglycerol in the cell wall (32). Neisseria gonorrhoeae utilizes an efflux pump to expel cathelicidin, avoiding accumulation of bactericidal levels (33). Enterococcus faecalis, S. pyogenes, Salmonella enterica and Proteus mirabilis produce proteinases that are capable of degrading human cathelicidin LL-37 (34). Certain strains of S. pyogenes also secrete a complement-inhibitory protein known as SIC that recently has been shown to bind LL-37 and block its antimicrobial activity. Finally, pathogenic Shigellae possess a unique strategy to avoid cathelicidin killing, down-regulating colonic epithelial cell production of LL-37 at the mRNA level (35).

For some of the above pathogens, isogenic mutants have been identified that exhibit increased cathelicidin sensitivity in vitro compared with the wild-type parent strain. These mutants have been studied in animal models of infection providing suggestive data that cathelicidin resistance itself contributes to virulence potential. Dlt ${ }^{-}$and $\mathrm{MprF}^{-} \mathrm{mu}-$ tants of S. aureus lack D-alanine and L-lysine cell-wall modifications, respectively, and are more sensitive to cathelicidins in vitro. Both types of mutants are more readily phagocytosed by neutrophils and less able to establish systemic infection in mice $(36,37)$. Salmonella enterica mutants in PmrA lack the aminoarabinose modification of LPS associated with cathelicidin resistance and are less virulent in a murine enteric infection model (38). One study of S. pyogenes pathogenicity approached the issue from the opposite perspective. This bacterium is normally sensitive to human LL-37 or murine CRAMP killing, but resistant mutants can be selected by serial exposure to cathelicidin in vitro. Upon subcutaneous inoculation of mice, the CRAMPresistant S. pyogenes mutant was found to induce rapidly spreading necrotic skin infections, whereas the wild-type parent bacterium produced smaller localized ulcerations (39).

Further data linking endogenous cathelicidin peptide production to innate immune defense come from studies in which specific host pathways for cathelidin activation or inactivation are manipulated. For example, a specific inhibitor of neutrophil elastase was used to block the proteolytic activation of protegrin in porcine skin. Administration of this inhibitor significantly decreased the ability of pigs to clear bacteria from skin wounds, while subsequent treatment with the calculated amount of intact protegrin normalized in vivo antimicrobial activity (40). Mice with a knockout of neutrophil elastase exhibit neutrophil killing 
defects and are more susceptible to S. aureus and C. albicans infections (41). It is interesting to speculate that impaired proteolytic activation of neutrophil granule cathelicidins contributes to the immunodeficient phenotype of the knockout mice, but this hypothesis remains to be tested. Shedding of heparan sulfate cell-surface proteoglycans can interfere with cathelicidin function. The pathogen P. aeruginosa, through its virulence factor LasA, enhances in vitro shedding of the proteoglycan syndecan-1 (42). Newborn mice deficient in syndecan-1 resist $\mathrm{P}$. aeruginosa lung infection but become susceptible when treated with syndecan-1-derived heparan sulfate chains (43).

Additional experimental evidence indicates that augmentation of cathelicidin levels on host mucosal surfaces can retard bacterial colonization and enhance resistance to infection. Mice treated intratracheally with an adenoviralLL37 vector had a lower bacterial load and diminished inflammatory response after P. aeruginosa challenge compared with untreated controls (44). In lambs with pneumonia, intratracheal administration of cathelicidin reduced the concentration of bacteria in both bronchoalveolar lavage fluid and consolidated pulmonary tissues (45). Topical administration of a gel containing a porcine cathelicidin was shown to inhibit development of wound infections in pigs (46).

Overexpression or supplementation studies do not, however, prove that the endogenous level of cathelicidin production by a mammalian host is sufficient to establish effective innate immunity against bacterial pathogens. The application of knockout mouse technology to the field of cathelicidin research is beginning to provide such evidence. A mouse deleted for the gene encoding the only mouse cathelicidin CRAMP exhibits normal growth and development and produces normal numbers of circulating leukocytes (39). Yet, blood and isolated mast cells from CRAMPknockout are notably deficient in killing the pathogen S. pyogenes, and knockout mice challenged with this bacterium develop much more severe and persistent necrotizing skin infections than their wild-type littermates $(22,39)$. Thus, cathelicidin, which is induced adaptively in the skin following cutaneous injury or S. pyogenes infection (25), appears to serve a critical innate defense function against invasive bacterial infection.

\section{CATHELICIDINS IN HUMAN CLINICAL DISEASE}

The previous section reviewed recent in vitro and in vivo experimental evidence that points to an important role for cathelicidins in mammalian innate defense. These discoveries have prompted clinical investigators to study how normal or abnormal patterns of cathelicidin expression can be linked to human disease pathogenesis. Production of cathelicidin is increased adaptively in response to a number of specific infections and in response to acute damage to the epithelial barrier. Conversely, increased production of these molecules is also associated with certain chronic inflammatory disorders, reflecting the dual functions of cathelicidins in immune activation (15). Investigators are also asking whether decreased cathelicidin production or interference with cathelicidin function may be evident in primary immunodeficiencies, or explain the increased infectious risks associated with certain injuries (e.g. burns) or chronic diseases (e.g. cystic fibrosis).

Certain infectious disease conditions in humans trigger local production of cathelicidins by epithelial cells and infiltrating leukocytes. LL-37 is up-regulated in the nasal mucosal of patients with chronic rhinitis (47), while in the lower respiratory tract, high concentrations of LL-37 are found in the bronchoalveolar lavage (BAL) fluid of infants with pneumonia (48). Biopsies of patients with bacillary dysentery produced by Shigella spp. reveal down-regulation of cathelicidin production, suggesting a potential virulence property of the bacteria to subvert innate immune defenses of the gastrointestinal mucosa (35).

A wide variety of skin disorders has been examined for changes in the pattern of cathelicidin expression at the epidermal barrier. LL-37 expression is increased in the inflammatory skin lesions of erythema toxicum neonatorum, with immunolocalization of the peptide within CD15expressing neutrophils, EG2-expressing eosinophils and CD1a-expressing dendritic cells (49). LL-37 expression is also induced within the epidermis during development of verruca vulgaris or condyloma accuminata, suggesting that the cathelicidin represents a component of the immunological response to papillomavirus infection (50). Differential expression of antimicrobial peptides appears to play a determinative role in the susceptibility of chronic inflammatory skin disorders to infectious complications. In psoriasis, cathelicidin levels are elevated and secondary infection is rare, whereas in atopic dermatitis cathelicidin expression is deficient and bacterial or viral superinfection is common (51). Relevant in this regard is the proven activity of human cathelicidin against $\mathrm{S}$. pyogenes (25) and the synergistic activity of human cathelidicin together with $\beta$-defensin against $\mathrm{S}$. aureus (51), the leading agents of superficial and invasive skin infection in humans.

Cathelicidin is produced in high levels in skin postwounding and is strongly expressed in healing skin epithelium, and antibody against this antimicrobial peptide inhibits re-epithelialization in a dose-dependent manner $(25,52)$. In chronic ulcers, LL-37 levels are low and absent in the ulcer edge epithelium (52). Thus, it appears that cathelicidins are important in successful wound closure and defects in their production can be correlated with development of chronic ulcers. Cathelicidin production is increased in the skin of newborn mice and humans compared with adults, representing a compensatory increase in innate immune defense capability during a period when cellular immune defenses are still immature (53). 
The chronic inflammation of cystic fibrosis (CF) is also associated with increased levels of cathelicidin in respiratory tract secretions. However, the CF airway surface fluid is diminished in its ability to kill bacteria. This defect is reflected in chronic high-level bacterial colonization and recurrent pneumonia with organisms such as $\mathrm{P}$. aeruginosa. The bacterial killing ability of CF airway fluid is restored when its salt concentration is lowered to normal levels, suggesting that the abnormally high salt concentrations produced by the defective $\mathrm{CF}$ transmembrane conductance regulator may be responsible (54). The bacterial killing ability of epithelial-derived antimicrobial peptides such as LL-37 is inactivated by high salt concentrations $(55,56)$, suggesting that a defect in this component of innate immune defense may be responsible for the chronic pulmonary infections seen in CF patients. In vitro experiments suggest that a gene therapy approach may one day be used to address this problem: while the airway surface fluid of cystic fibrosis xenografts failed to kill P. aeruginosa or S. aureus, exposure of the xenografts to an adenovirus expressing human cathelicidin restored bacterial killing to normal levels (44).

Recently, an association between oral disease and cathelicidins was shown in patients with Kostmann syndrome, a severe congenital neutropenia. These patients are treated with granulocyte-colony-stimulating factor to increase neutrophil counts within the normal range. Nevertheless, patients with Kostmann syndrome still experience frequent infections and develop periodontal disease. Functional analysis of neutrophils isolated from these patients demonstrated normal oxidative burst function, but revealed a lack of measurable cathelicidin (57). Several of the original index cases in the Kostmann family were recently shown to harbor mutations in the neutrophil elastase gene, suggesting a mechanism for a lack of cathelicidin processing and activation (58).

\section{CONCLUSIONS AND FUTURE PROSPECTS}

Diverse biological functions have been documented for cathelicidins in microbial killing and augmentation of innate immune functions (Fig. 3). Clinical studies are now identifying associations between changes in cathelicidin production or function and human infectious diseases, inflammatory syndromes or immune deficiencies. A thorough understanding of these associations will pave the way for treatment strategies involving administration of exogenous cathelicidin or modulation of endogenous cathelicidin production. Indeed, clinical trials have already tested the efficacy of oral administration of synthetic cathelicidin derivatives in cancer patients to prevent chemotherapy-induced mucositis (59). Butyrate and other short-chain fatty acids have been shown to up-regulate colonocyte production of LL-37, providing an initial rationale for dietary modulation of innate mucosal immunity (60). In the coming years, we will learn more about how impaired cathelicidin activity on

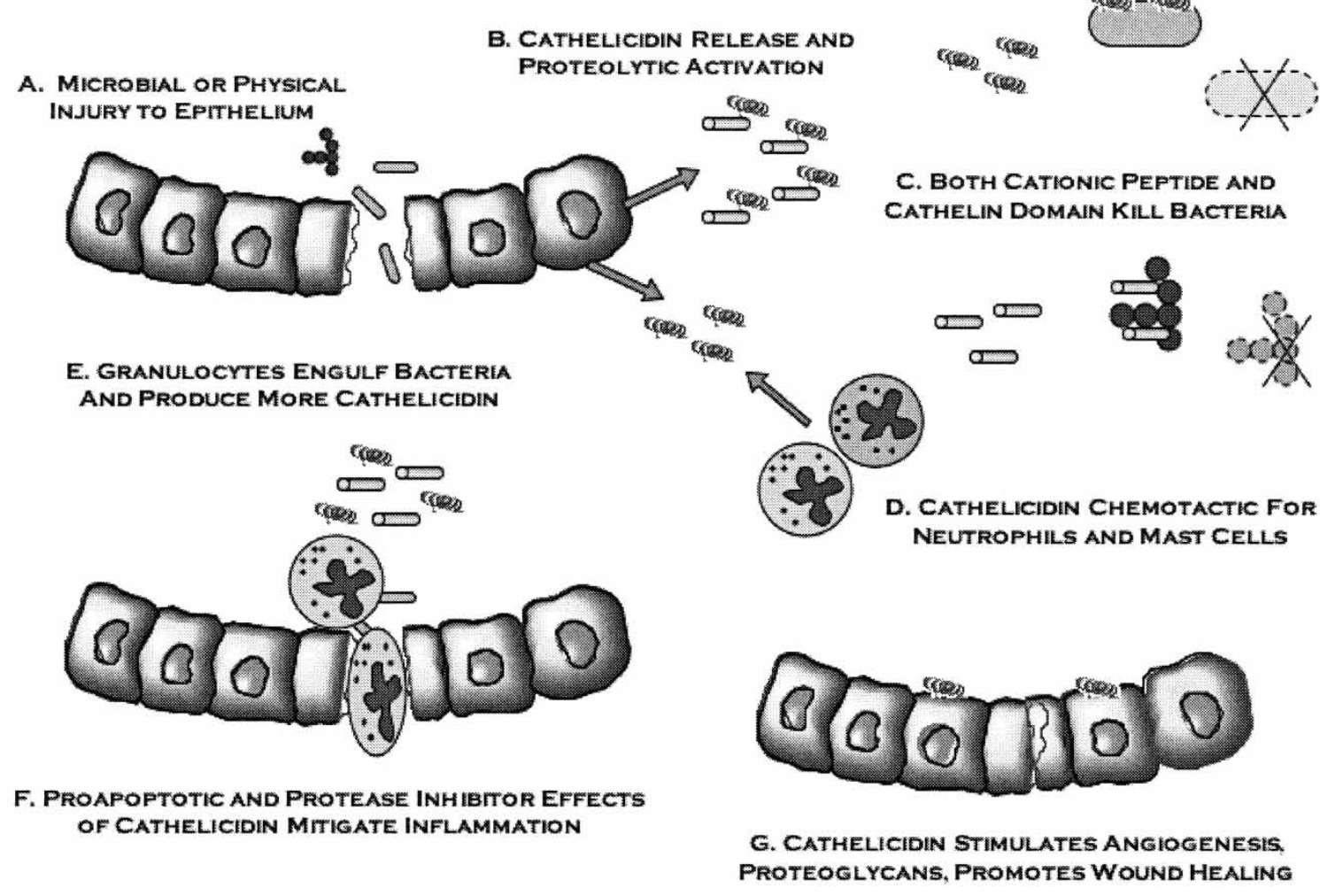

Fig. 3. Multiple biological functions of cathelicidins that function in innate defense of host epithelial surfaces against bacterial infection. 
mucosal tissues predisposes to infectious complications, how resistance to cathelicidin killing represents a defining feature of certain invasive microbial pathogens, and how dysregulated cathelicidin expression may contribute to chronic inflammatory disorders. Further knowledge regarding basic cathelicidin structure-function interactions and regulatory pathways will allow physicians and researchers to exploit the diverse biological functions of these peptides towards improved medical diagnosis and therapy.

\section{REFERENCES}

1. Ramanathan B, Davis EG, Ross CR, Blecha F. Cathelicidins: microbicidal activity, mechanisms of action, and roles in innate immunity. Microbes Infect 2002; 4: 361-72.

2. Zaiou M, Gallo RL. Cathelicidins, essential gene-encoded mammalian antibiotics. J Mol Med 2002; 80: 549-61.

3. Zanetti M, Gennaro R, Scocchi M, Skerlavaj B. Structure and biology of cathelicidins. Adv Exp Med Biol 2000; 479: 203-18.

4. Gennaro R, Zanetti M. Structural features and biological activities of the cathelicidin-derived antimicrobial peptides. Biopolymers 2000; 55: 31-49.

5. Panyutich A, Shi J, Boutz PL, Zhao C, Ganz T. Porcine polymorphonuclear leukocytes generate extracellular microbicidal activity by elastase-mediated activation of secreted proprotegrins. Infect Immun 1997; 65: 978-85.

6. Sorensen OE, Follin P, Johnsen AH, Calafat J, Tjabringa GS, Hiemstra PS, Borregaard N. Human cathelicidin, hCAP-18, is processed to the antimicrobial peptide LL-37 by extracellular cleavage with proteinase 3. Blood 2001; 97: 3951-9.

7. Gudmundsson GH, Agerberth B, Odeberg J, Bergman T, Olsson $\mathrm{B}$, Salcedo R. The human gene FALL39 and processing of the cathelin precursor to the antibacterial peptide LL-37 in granulocytes. Eur J Biochem 1996; 238: 325-32.

8. Larrick JW, Hirata M, Balint RF, Lee J, Zhong J, Wright SC. Human CAP18: a novel antimicrobial lipopolysaccharide-binding protein. Infect Immun 1995; 63: 1291-7.

9. Gallo RL, Kim KJ, Bernfield M, Kozak CA, Zanetti M, Merluzzi L, Gennaro R. Identification of CRAMP, a cathelinrelated antimicrobial peptide expressed in the embryonic and adult mouse. J Biol Chem 1997; 272: 13088-93.

10. Pestonjamasp VK, Huttner KH, Gallo RL. Processing site and gene structure for the murine antimicrobial peptide CRAMP. Peptides 2001; 22: 1643-50.

11. Zanetti M, Gennaro R, Skerlavaj B, Tomasinsig L, Circo R. Cathelicidin peptides as candidates for a novel class of antimicrobials. Curr Pharm Des 2002; 8: 779-93.

12. Oren Z, Lerman JC, Gudmundsson GH, Agerberth B, Shai Y. Structure and organization of the human antimicrobial peptide LL-37 in phospholipid membranes: relevance to the molecular basis for its non-cell-selective activity. Biochem J 1999; 341: 501-13.

13. Gutsmann T, Hagge SO, Larrick JW, Seydel U, Wiese A. Interaction of CAP18-derived peptides with membranes made from endotoxins or phospholipids. Biophys J 2001; 80: 2935-45.

14. Boman HG, Agerberth B, Boman A. Mechanisms of action on Escherichia coli of cecropin P1 and PR-39, two antibacterial peptides from pig intestine. Infect Immun 1993; 61: 2978-84.

15. Gallo RL, Murakami M, Ohtake T, Zaiou M. Biology and clinical relevance of naturally occurring antimicrobial peptides. $\mathbf{J}$ Allergy Clin Immunol 2002; 110: 823-31.

16. Ciornei CD, Egesten A, Bodelsson M. Effects of human cathelicidin antimicrobial peptide LL-37 on lipopolysacchar- ide-induced nitric oxide release from rat aorta in vitro. Acta Anaesthesiol Scand 2003; 47: 213-20.

17. Sawa T, Kurahashi K, Ohara M, Gropper MA, Doshi V, Larrick JW, Wiener-Kronish JP. Evaluation of antimicrobial and lipopolysaccharide-neutralizing effects of a synthetic CAP18 fragment against Pseudomonas aeruginosa in a mouse model. Antimicrob Agents Chemother 1998; 42: 3269-75.

18. Scott MG, Davidson DJ, Gold MR, Bowdish D, Hancock RE. The human antimicrobial peptide LL-37 is a multifunctional modulator of innate immune responses. J Immunol 2002; 169: 3883-91.

19. De Y, Chen Q, Schmidt AP, Anderson GM, Wang JM, Wooters $\mathrm{J}$, et al. LL-37, the neutrophil granule- and epithelial cell-derived cathelicidin, utilizes formyl peptide receptor-like 1 (FPRL1) as a receptor to chemoattract human peripheral blood neutrophils, monocytes, and T cells. J Exp Med 2000; 192: 1069-74.

20. Niyonsaba F, Iwabuchi K, Someya A, Hirata M, Matsuda H, Ogawa H, Nagaoka I. A cathelicidin family of human antibacterial peptide LL-37 induces mast cell chemotaxis. Immunology 2002; 106: 20-6.

21. Turner J, Cho Y, Dinh NN, Waring AJ, Lehrer RI. Activities of LL-37, a cathelin-associated antimicrobial peptide of human neutrophils. Antimicrob Agents Chemother 1998; 42: 2206-14.

22. Di Nardo A, Vitiello A, Gallo RL. Cutting edge: mast cell antimicrobial activity is mediated by expression of cathelicidin antimicrobial peptide. J Immunol 2003; 170: 2274-8.

23. Murakami M, Ohtake T, Dorschner RA, Gallo RL. Cathelicidin antimicrobial peptides are expressed in salivary glands and saliva. J Dent Res 2002; 81: 845-50.

24. Murakami M, Ohtake T, Dorschner RA, Schittek B, Garbe C, Gallo RL. Cathelicidin anti-microbial peptide expression in sweat, an innate defense system for the skin. J Invest Dermatol 2002; 119: 1090-5.

25. Dorschner RA, Pestonjamasp VK, Tamakuwala S, Ohtake T, Rudisill J, Nizet V, et al. Cutaneous injury induces the release of cathelicidin anti-microbial peptides active against group A Streptococcus. J Invest Dermatol 2001; 117: 91-7.

26. Wu H, Zhang G, Minton JE, Ross CR, Blecha F. Regulation of cathelicidin gene expression: induction by lipopolysaccharide, interleukin-6, retinoic acid, and Salmonella enterica serovar typhimurium infection. Infect Immun 2000; 68: 5552-8.

27. Tomasinsig L, Scocchi M, Di Loreto C, Artico D, Zanetti M. Inducible expression of an antimicrobial peptide of the innate immunity in polymorphonuclear leukocytes. J Leukoc Biol 2002; 72: $1003-10$.

28. Zaiou M, Nizet V, Gallo RL. Antimicrobial and protease inhibitory functions of the human cathelicidin (hCAP18/LL37) prosequence. J Invest Dermatol 2003; 120: 810-6.

29. Risso A, Zanetti M, Gennaro R. Cytotoxicity and apoptosis mediated by two peptides of innate immunity. Cell Immunol 1998; 189: 107-15.

30. Gunn JS, Ryan SS, Van Velkinburgh JC, Ernst RK, Miller SI. Genetic and functional analysis of a PmrA-PmrB-regulated locus necessary for lipopolysaccharide modification, antimicrobial peptide resistance, and oral virulence of Salmonella enterica serovar typhimurium. Infect Immun 2000; 68: 6139-46.

31. Lysenko ES, Gould J, Bals R, Wilson JM, Weiser JN. Bacterial phosphorylcholine decreases susceptibility to the antimicrobial peptide LL-37/hCAP18 expressed in the upper respiratory tract. Infect Immun 2000; 68: 1664-71.

32. Peschel A. How do bacteria resist human antimicrobial peptides? Trends Microbiol 2002; 10: 179-86.

33. Shafer WM, Qu X, Waring AJ, Lehrer RI. Modulation of Neisseria gonorrhoeae susceptibility to vertebrate antibacterial peptides due to a member of the resistance/nodulation/division efflux pump family. Proc Natl Acad Sci USA 1998; 95: 1829-33. 
34. Schmidtchen A, Frick IM, Andersson E, Tapper H, Bjorck L. Proteinases of common pathogenic bacteria degrade and inactivate the antibacterial peptide LL-37. Mol Microbiol 2002; 46: 157-68.

35. Islam D, Bandholtz L, Nilsson J, Wigzell H, Christensson B, Agerberth B, Gudmundsson G. Downregulation of bactericidal peptides in enteric infections: a novel immune escape mechanism with bacterial DNA as a potential regulator. Nat Med 2001; 7 : $180-5$.

36. Collins LV, Kristian SA, Weidenmaier C, Kristian SA, Weidenmaier C, Faigle M, et al. Staphylococcus aureus strains lacking D-alanine modifications of teichoic acids are highly susceptible to human neutrophil killing and are virulence attenuated in mice. J Infect Dis 2002; 186: 214-9.

37. Kristian SA, Durr M, Van Strijp JA, Neumeister B, Peschel A. MprF-mediated lysinylation of phospholipids in Staphylococcus aureus leads to protection against oxygen-independent neutrophil killing. Infect Immun 2003; 71: 546-9.

38. Guina T, Yi EC, Wang H, Hackett M, Miller SI. A PhoPregulated outer membrane protease of Salmonella enterica serovar typhimurium promotes resistance to alpha-helical antimicrobial peptides. J Bacteriol 2000; 182: 4077-86.

39. Nizet V, Ohtake T, Lauth X, Trowbridge J, Rudisill J, Dorschner $\mathrm{RA}$, et al. Innate antimicrobial peptide protects the skin from invasive bacterial infection. Nature 2001; 414: 454-7.

40. Cole AM, Shi J, Ceccarelli A, Kim YH, Park A, Ganz T. Inhibition of neutrophil elastase prevents cathelicidin activation and impairs clearance of bacteria from wounds. Blood 2001; 97 : 297-304.

41. Reeves EP, Lu H, Jacobs HL, Messina CG, Bolsover S, Gabella $\mathrm{G}$, et al. Killing activity of neutrophils is mediated through activation of proteases by $\mathrm{K}^{+}$flux. Nature 2002; 416: 291-7.

42. Park PW, Pier GB, Preston MJ, Goldberger O, Fitzgerald ML, Bernfield M. Syndecan-1 shedding is enhanced by LasA, a secreted virulence factor of Pseudomonas aeruginosa. J Biol Chem 2000; 275: 3057-64.

43. Park PW, Pier GB, Hinkes MT, Bernfield M. Exploitation of syndecan-1 shedding by Pseudomonas aeruginosa enhances virulence. Nature 2001; 411: 98-102.

44. Bals R, Weiner DJ, Moscioni AD, Meegalla RL, Wilson JM. Augmentation of innate host defense by expression of a cathelicidin antimicrobial peptide. Infect Immun 1999; 67: 6084-9.

45. Brogden KA, Kalfa VC, Ackermann MR, Palmquist DE, McCray Jr PB, Tack BF. The ovine cathelicidin SMAP29 kills ovine respiratory pathogens in vitro and in an ovine model of pulmonary infection. Antimicrob Agents Chemother 2001; 45: $331-4$.

46. Ceccarelli AV, Cole AM, Park AK, Tahk S, Yoshioka D, Ganz T. Therapeutic effect of a pig-derived peptide antibiotic on porcine wound infections. Comp Med 2001; 51: 75-9.
47. Kim ST, Cha HE, Kim DY, Han GC, Chung YS, Lee YJ, et al. Antimicrobial peptide LL-37 is upregulated in chronic nasal inflammatory disease. Acta Otolaryngol 2003; 123: 81-5.

48. Schaller-Bals S, Schulze A, Bals R. Increased levels of antimicrobial peptides in tracheal aspirates of newborn infants during infection. Am J Respir Crit Care Med 2002; 165: 992-5.

49. Marchini G, Lindow S, Brismar H, Stabi B, Berggren V, Ulfgren $\mathrm{AK}$, et al. The newborn infant is protected by an innate antimicrobial barrier: peptide antibiotics are present in the skin and vernix caseosa. Br J Dermatol 2002; 147: 1127-34.

50. Conner K, Nern K, Rudisill J, O'Grady T, Gallo RL. The antimicrobial peptide LL-37 is expressed by keratinocytes in condyloma acuminatum and verruca vulgaris. J Am Acad Dermatol 2002; 47: 347-50.

51. Ong PY, Ohtake T, Brandt C, Strickland I, Boguniewicz M, Ganz T, et al. Endogenous antimicrobial peptides and skin infections in atopic dermatitis. N Engl J Med 2002; 347: 115160.

52. Heilborn JD, Nilsson MF, Kratz G, Weber G, Sorensen O, Borregaard N, Stahle-Backdahl M. The cathelicidin antimicrobial peptide LL-37 is involved in re-epithelialization of human skin wounds and is lacking in chronic ulcer epithelium. $\mathbf{J}$ Invest Dermatol 2003; 120: 379-89.

53. Dorschner RA, Lin KH, Murakami M, Gallo RL. Neonatal skin in mice and humans expresses increased levels of antimicrobial peptides: innate immunity during development of the adaptive response. Pediatr Res 2003; 53: 566-72.

54. Smith JJ, Travis SM, Greenberg EP, Welsh MJ. Cystic fibrosis airway epithelia fail to kill bacteria because of abnormal airway surface fluid. Cell 1996; 85: 229-36.

55. Goldman MJ, Anderson GM, Stolzenberg ED, Kari UP, Zasloff M, Wilson JM. Human beta-defensin-1 is a salt-sensitive antibiotic in lung that is inactivated in cystic fibrosis. Cell 1997; 88: 553-60.

56. Bals R, Wang X, Zasloff M, Wilson JM. The peptide antibiotic LL-37/hCAP-18 is expressed in epithelia of the human lung where it has broad antimicrobial activity at the airway surface. Proc Natl Acad Sci USA 1998; 95: 9541-6.

57. Putsep K, Carlsson G, Boman HG, Andersson M. Deficiency of antibacterial peptides in patients with morbus Kostmann: an observation study. Lancet 2002; 360: 1144-9.

58. Aprikyan AA, Carlsson G, Stein S, Oganesian A, Fadeel B, Dale DC, et al. Neutrophil elastase mutations in severe congenital neutropenia patients of the original Kostmann family. Blood

59. Chen J, Falla TJ, Liu H, Falla TJ, Liu H, Hurst MA, et al. Development of protegrins for the treatment and prevention of oral mucositis: structure-activity relationships of synthetic protegrin analogues. Biopolymers 2000; 55: 88-98.

60. Schauber J, Svanholm C, Termen S, Iffland K, Menzel T, Scheppach W, et al. Expression of the cathelicidin LL-37 is modulated by short chain fatty acids in colonocytes: relevance of signalling pathways. Gut 2003; 52: 735-41.

Submitted May 16, 2003; accepted June 6, 2003 